\title{
Individual variation and constraints on language learning
}

\author{
Colin Phillips \\ University of Maryland
}

If I had chosen to speak Chinese to my daughter instead of English, she would have grown up speaking differently than she does now. If I had chosen to speak to her only with loud music in the background, then it would be no surprise if her language development was delayed. And I wouldn't expect much better results if I had only spoken to her when she was engrossed in some other activity. This is all rather obvious. Children learn the language that they are exposed to; dramatic corruption of the input affects what they can learn from it; and it helps when children attend to what people say to them. So it is surprising indeed to read that theories of language learning are seriously undermined by the finding that different language input leads to different learning outcomes. Yet this is what Ewa Dąbrowska claims here and in other works. This is unfortunate. Dąbrowska and her colleagues are making valuable discoveries about the scope of language abilities across the population, and these results should be relevant to any model of language learning. But by using these findings to fuel the tension between socalled 'generative' and 'usage-based' accounts of language learning little progress is made. Much more could be gained by probing more deeply into the source of individual differences.

Dąbrowska finds that adults with different educational backgrounds perform differently in tasks that require attention to morphological, syntactic, or semantic details. Speakers with low academic achievement are less likely to comprehend implausible passives (The dog was bitten by the man), sentences with sentential subjects (Paul noticed that the fact that the room was tidy surprised Shona), or sentences with universal quantifiers (Every fish is in a bowl). She argues that the individual differences in comprehension profiles reflect different grammatical endstates in learners of the same language. Additionally, she argues that this evidence challenges what she refers to as the Convergence Argument, which she regards as "one of the strongest arguments for an innate language faculty." The convergence 
argument is described as "the assertion that all learners converge on more or less the same grammar," despite differences in input. Dąbrowska regards her evidence as a challenge for the notion of an innate language faculty, but I think that its main interest lies elsewhere.

\section{Individual differences and prerequisites for learning}

Dąbrowska makes the important observation that mere exposure to relevant sentences is no guarantee that a learner will draw appropriate inferences based upon those sentences. In order to be useful for learning, a sentence must generally occur in a situation where the learner can grasp both its form and its meaning. Also, the learner must attend to that form-meaning relation. This list of prerequisites should probably be expanded to include the following six components.

a. The learner must be exposed to relevant linguistic input (Input I)

b. The learner must experience that input in suitably informative contexts (Input II)

c. The learner must attend to these informative situations (Uptake I)

d. The learner must appropriately encode these informative situations (Uptake II)

e. The learner must store relevant examples and perform appropriate computations over them, in order to form grammatical hypotheses (Computation I)

f. The learner's computations may be guided by a constrained hypothesis space (Computation II)

Component (f) is what is sometimes known as the Universal Grammar hypothesis (Chomsky, 1986; Snyder, 2007), though the general idea surfaces under other guises (Saffran, 2003; Newport \& Aslin, 2004). But all six prerequisites contribute to the learner's endstate, and therefore variation in any of them could lead to variation in the endstate. It is an empirical question how much variation can be tolerated in any of the components before a different endstate obtains. Dąbrowska appears to favor components (a-c) as the source of the effects of different educational attainment. These are plausible sources of variation. But it is also conceivable that there might be variation in (d-f), either as a consequence of experience or as a consequence of genetic variation (cf. Wijnen in press, on atypical language development). We currently know too little about individual differences to know which of these components plays a more important role, and this should be an interesting area for developing more explicit hypotheses in the future. 


\section{The main argument}

In contrast, I see little merit in the argument that Dąbrowska chooses to focus on, namely the claim that individual differences undermine the evidence for constraints on the learner's hypothesis space ('Universal Grammar'). Her argument can be paraphrased as follows:

Since speakers with very different language experience/abilities perform differently in certain language tasks, there is no need for constraints on learners' hypothesis space.

In light of the list of prerequisites for learning, it should be clear that this argument does not work particularly well. There are many reasons why speakers with greatly different language experience and different educational levels might perform differently in complex language tasks. So it is hard to see how we can draw clear conclusions from this about the scope of constraints on learners' hypothesis space (i.e., component (f)). As such, Dąbrowska's argument is a non sequitur, and a distraction from the more interesting task of precisely identifying the source of individual differences.

\section{What is the Universal Grammar hypothesis?}

The UG hypothesis is a provocative name for the idea that there are constraints on the hypotheses that learners entertain. It is not a claim that learners do not need to learn. Experience is obviously necessary. However, we still know very little about how much experience is needed for successful learning, and how much variation in experience is needed to yield different learning outcomes. This is an important question that Dąbrowska's work may begin to contribute to. But the mere observation of individual variation provides no evidence against constraints on the learner's hypothesis space. Any serious UG hypothesis assumes that experience plays an important role in determining which hypotheses the learner chooses, for the simple reason that languages (and dialects) vary.

\section{What is the Convergence Argument?}

Dąbrowska assumes that great theoretical importance is attached to the claim that learning outcomes are identical across widely varying language experience. The idea is that this insensitivity to varying input is necessary for motivating constraints on the learner's hypothesis space. This is not, in fact, needed. Arguments 
for a constrained hypothesis space can be made without any variation in the input. For a finite set of input utterances, a vast array of grammatical hypotheses are compatible with those input utterances. If learrers consistently reach the same conclusion based on the same input utterances, despite the many possible conclusions that they could draw, then it suggests that there are constraints on the conclusions that they draw.

So where does varied input enter the argument? If there are constraints on learners' hypotheses, then it is likely that those constraints would lead learners to the same conclusion, even if there are limited differences in the input. How big can the differences in the input be before learners start to reach different conclusions? We do not yet know. If the input differences are large enough, then learners will arrive at a different language or dialect. If the input differences are small, learners may or may not arrive at the same conclusion. These are interesting and important questions, but they do not undermine the existence of constraints on the learner.

\section{What do the experiments show?}

Dąbrowska argues that her results show that speakers with different backgrounds have arrived at different grammatical endstates. She argues against alternative claims that the speakers simply differ in their ability to carry out certain language tasks. Two points of clarification are needed here.

First, there is a need to clarify what counts as 'linguistic knowledge', as Dąbrowska's argument may be creating a dispute where there is none. We should distinguish between (i) the representations that a speaker can construct or accept as well-formed, regardless of how hard it might be to construct those representations; and (ii) the speaker's skill or efficiency at constructing specific representations or interpretations. This distinction is relevant for all linguists, irrespective of whether they view (i) or (ii) as more important. Rightly or wrongly, many linguists focus on type (i) when referring to 'linguistic knowledge'. Dąbrowska regards type (ii) as another important component of linguistic knowledge, whereas many linguists would view it as a property of the language processing system. This is a simple terminological ambiguity. But it is not helpful to construct arguments that rely on this terminological ambiguity. If anything, Dąbrowska's evidence (in English) demonstrates variation across speakers in type (ii) knowledge. But she uses this variation to criticize arguments about knowledge of type (i). She presents interesting evidence that training can rapidly change adults' ability to comprehend certain sentence types, but this training is almost certainly changing ability type (ii). So it is not clear how this has any bearing on arguments about UG, which (unfortunately) have almost entirely focused on type (i) knowledge. 
Second, Dąbrowska's findings with adults are reminiscent of many findings in the child language literature of the past 30 years. In many cases, initial findings of poor performance suggested that children lack some element of linguistic knowledge (e.g., Tavakolian, 1978; Stager \& Werker, 1997) only for subsequent experimental refinements to show that the initial reports had underestimated children's abilities (Crain \& McKee, 1986; Conroy, Takahashi, Lidz, \& Phillips, 2009; Yoshida, Fennell, Swingley, \& Werker, 2009). It would be very interesting to apply the same experimental refinements that have worked with children to the diverse adult populations that Dąbrowska investigates in her work. In addition, child studies are also now revealing that there are substantial constraints on the child language processor (Snedeker \& Trueswell, 2004; Mazuka, Jincho, \& Oishi, 2009), and researchers are beginning to examine how these limitations in language processing might impact the course of language learning (i.e., component (d) in the list above; Omaki, 2010). It would be interesting to know how much variation there is in the language processing abilities of the populations that Dąbrowska studies, and how this might impact their learning.

\section{References}

Chomsky, N. (1986). Knowledge of language: Its nature, origin, and use. New York, NY: Praeger. Conroy, A., Takahashi, E., Lidz, J., \& Phillips, C., 2009. Equal treatment for all antecedents: How children succeed with Principle B. Linguistic Inquiry, 40, 446-486.

Crain, S., \& McKee, C. (1986). The acquisition of structural restrictions on anaphora. In S. Berman, J.-W. Choe, \& J. McDonough (Eds.), Proceedings of the 16th North Eastern Linguistics Society (pp. 94-110). Amherst, MA: GLSA Publications.

Mazuka, R., Jincho, N., \& Oishi, H. (2009). Development of executive control and language processing. Language and Linguistics Compass, 3, 59-89.

Newport, E.L., \& Aslin, R.N. (2004). Learning at a distance: I. Statistical learning of non-adjacent dependencies. Cognitive Psychology, 48, 127-162.

Omaki, A. (2010). Commitment and flexibility in the developing parser. $\mathrm{PhD}$ dissertation, University of Maryland.

Saffran, J.R. (2003). Statistical language learning: Mechanisms and constraints. Current Directions in Psychological Science, 12, 110-114.

Snedeker, J., \& Trueswell, J.C. (2004). The developing constraints on parsing decisions: The role of lexical biases and referential scenes in child and adult sentence processing. Cognitive Psychology, 49, 238-299.

Snyder, W. (2007). Child language: The parametric approach. Oxford: Oxford University Press.

Stager, C.L., \& Werker, J.F. (1997). Infants listen for more phonetic detail in speech perception than in word-learning tasks. Nature, $388,381-382$.

Tavakolian, S. (1978). Children's comprehension of pronominal subjects and missing subjects in complicated sentences. In H. Goodluck \& L. Solan (Eds.), Papers in the structure and 
development of child language: University of Massachusetts Occasional Papers in Linguistics \#4. Amherst, MA: GLSA Publications.

Wijnen, F. (in press). Acquisition of linguistic categories: Cross-domain convergences. In J. Boluis \& M. Everaert (Eds.), Birdsong, speech and language: Converging mechanisms. Cambridge, MA: MIT Press.

Yoshida, K., Fennell, C., Swingley, D., \& Werker, J.F. (2009). 14-month-olds learn phonetically similar words. Developmental Science, 12, 412-418.

\author{
Author's address \\ Colin Phillips \\ Department of Linguistics \\ Neuroscience and Cognitive Science Program \\ University of Maryland \\ 1401 Marie Mount Hall \\ College Park, MD 20742 \\ colin@umd.edu
}

